
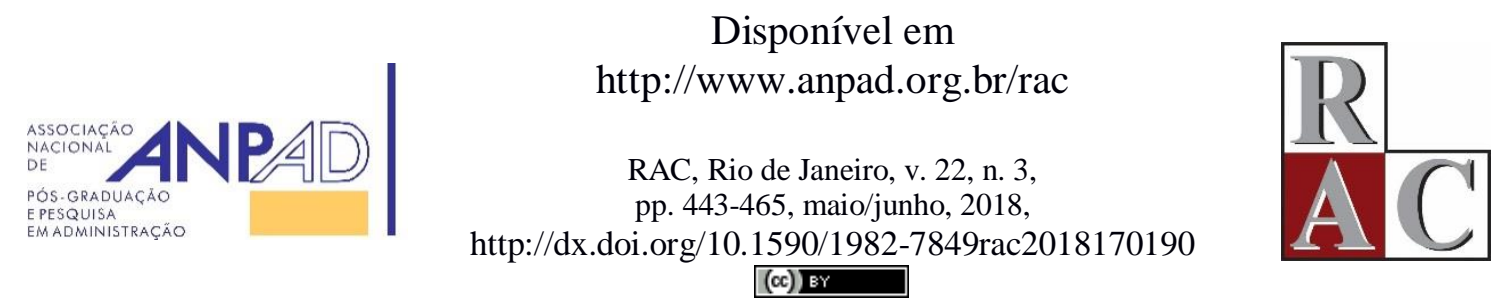

Artigos Tecnológicos:

\title{
Concursos Públicos Docentes em uma Universidade Federal: Proposta de Melhorias em Software
} Civil Service Competition for Professors at a Federal University: Proposal for Software
Improvements

Matheus Boni Barbosa ${ }^{1}$ Elvis Silveira-Martins ${ }^{1}$ Universidade Federal de Pelotas, Departamento de Administração, Pelotas, RS, Brasil ${ }^{1}$

Artigo recebido em 25.06.2017. Última versão recebida em 08.01.2018. Aprovado em 02.02.2018. Editor Associado: Prof. Gustavo da Silva Motta 


\title{
Resumo
}

O presente trabalho propõe um plano de intervenção para a solução de dificuldades e de melhorias relativas ao processo de realização de provas em Concursos Públicos e Processos Seletivos em uma Universidade Federal. As propostas foram motivadas, principalmente, devido a uma série de equívocos pontuais encontrados em registros documentais, provenientes da interação entre o Software que gerencia as tarefas das seleções e os usuários desse sistema, levando a necessidade de confecção de documentos específicos para regularização dos processos. Embora não trazendo prejuízos do ponto de vista finalístico, essas ações elevam o tempo despendido e o número de atividades anteriores à homologação dos resultados dos certames. Identificou-se, portanto, a necessidade de compreensão dos problemas de forma mais aguda, e o foco do diagnóstico foi direcionado àqueles fatores que estavam trazendo maior impacto ao processo. A metodologia adotada envolveu pesquisa bibliográfica, análise documental e a observação participante sobre os fluxos dos processos. O resultado foi uma proposta de intervenção para atuar sobre as funcionalidades atuais do Software, para se criarem novas funcionalidades e para promover a integração do Software ao portfólio institucional, permitindo atuar eficazmente na correção e na prevenção de equívocos, bem como na melhoria dos processos.

Palavras-chave: concursos públicos; desenvolvimento de software; sistema de informação; proposta de melhorias.

\begin{abstract}
This research proposes an intervention plan for solving difficulties and offering improvements related to the Civil Service testing and selection process for professors at a Brazilian Federal University. The proposals were motivated, mainly, due to a series of occasional misunderstandings found in documentary records, resulting from the interaction between the software used to manage tasks in the selection process and the users of this system, leading to the necessity of producing specific documents to methodize the processes. Although not resulting in harm from a finalistic point of view, these actions increase the time spent and the number of activities before homologation of the results. There was, therefore, an intention to more acutely understand the problems, so the diagnosis focuses on those factors that had a greater impact on the process. The methodology adopted involved bibliographic research, document analysis and a participating observer in the processes. The result was an intervention proposal to act on the software's current functions, to create new functions and to promote integration of the software into the institutional portfolio, allowing effective action in the correction and prevention of problems and also improvements in the processes.
\end{abstract}

Key words: civil service tests; software development; information systems; intervention proposal. 


\section{Introdução}

Os Concursos Públicos e os Processos Seletivos para Docentes, regidos por legislação específica, constituem a forma de ingresso de professores efetivos e substitutos na carreira do magistério superior, respectivamente, nas Instituições Federais de Ensino Superior (IFES), englobando os Institutos Federais (IFs) e as Universidades Públicas, órgãos da Administração Pública Indireta. A Fundação Universidade Federal do Pampa (UNIPAMPA), situada na região sul do Estado do Rio Grande do Sul, Brasil, tem, dentre as suas particularidades, a distribuição de suas unidades acadêmicas em 10 campi. Esse modelo organizacional multicampi leva a criação de estruturas locais para atendimento das demandas afeitas. Neste sentido, o processo de realização de provas e títulos, objeto da análise, tem parte do planejamento e toda a execução descentralizada em Comissões Locais de Concursos (CLC's), sendo constituída uma por campus.

Como ferramenta de suporte à realização das seleções, as CLC's tem à disposição um Software, desenvolvido internamente, para acompanhamento das etapas e da geração dos documentos resultantes.

Essa iniciativa, ao introduzir uma inovação tecnológica no contexto dos processos dos Concursos Públicos e de Processos Seletivos Simplificados (PSS) docentes, representou grande avanço, à época, ao modificar a dinâmica da atuação dos responsáveis pela execução das provas, pois proporcionou ferramenta customizada para elaboração dos documentos relativos aos certames (atas, planilhas, listas de presença, pareceres, etc.), agilizando procedimentos operacionais, gerando como benefícios mais notáveis a redução nas inserções manuais e consequente uso mais produtivo do tempo e dos recursos disponíveis, além da visualização do encadeamento lógico das etapas.

O reconhecimento desses méritos, todavia, não exime o Software de estar sujeito a mudanças contínuas, qualidade intrínseca à sua natureza, de modo a receber alterações para manter-se sincronizado com seu ambiente social, jurídico e organizacional, sendo apropriado pensar que o Software deve ter seu conteúdo funcional progressivamente ampliado, durante seu ciclo de vida útil, perseguindo a satisfação dos seus usuários; portanto, encontra-se em evolução (Vasconcelos, Kimble, Carreteiro, \& Rocha, 2017).

Nesta linha, os equívocos pontuais inicialmente identificados em determinados registros documentais - que provocam ações corretivas no trâmite que culmina na homologação dos resultados dos certames - suscitaram a investigação mais profunda e o avanço desta pesquisa, corroborando com a necessidade de revisões e atualizações constantes do Software, em vistas de prover recursos adicionais que atendam adequadamente os usuários no cumprimento de suas tarefas. Na constatação de Fleischmann, Amirpur, Grupp, Benlian e Hess (2016), atualizações disponibilizadas em pacotes maiores (compostos por uma série de recursos novos), e menos frequentes, tendem a propiciar aumento na disposição de utilização do sistema pelo usuário, o qual as percebe como uma experiência positiva.

Não obstante, os processos em questão exigem atenções específicas do administrador, relacionadas a um conjunto de aspectos legais, técnicos e financeiro-orçamentários a serem controlados, inclusive o são externamente, vide a atuação do Tribunal de Contas da União (J. H. Silva, 2011). Portanto, é crucial trabalhar com sistemas de informações alinhados às normas, às disposições do edital, às resoluções e aos procedimentos internos, refletindo o devido respaldo legal, a transparência e a isonomia esperados de um processo seletivo público (Ivan et al., 2015).

Diante do exposto, este estudo tem como objetivo principal a proposição de melhorias em Software utilizado nos concursos públicos e processos seletivos da Universidade Federal do Pampa, com base na revisão de literatura especializada e em diagnóstico específico de problemas evidenciados nos registros das documentações provenientes da realização das provas, englobando concomitantemente os processos, as pessoas (usuários) e as tecnologias envolvidas. 
Com relação ao diagnóstico, foram utilizadas Erratas (material que regulariza as informações processuais) como fonte confiável para ponto de partida de identificação, mensuração e classificação dos problemas, sendo o período da amostra os anos de 2015 e 2016.

A proposta de intervenção, com soluções e alternativas para sanar e reduzir os problemas identificados, também intentou aproveitar as oportunidades de melhorias evolutivas do Software e presentes na própria estrutura física e técnica da Universidade, de modo a sustentar ações que visem tanto a maior agilidade na etapa de realização das provas quanto a proporcionar maior eficiência na etapa de conferência da documentação, posterior à etapa das provas e anterior à homologação dos resultados.

Portanto, adotaram-se técnicas e abordagens a partir das experiências profissionais e das práticas dos pesquisadores, as quais pudessem tanto identificar problemas quanto vislumbrar a construção de soluções direcionadas às provas e ao Software das seleções.

Os resultados alcançados podem contribuir para que a melhoria contínua se torne prática corrente na gestão dos concursos públicos e dos PSS da UNIPAMPA, essencialmente referente ao papel do Software. A incorporação das medidas sugeridas deve capacitá-lo para atuar em múltiplas fases dos processos, desde a integração de sistemas, que permita acesso aos dados dos candidatos inscritos, por exemplo, até servir de plataforma estatística para subsidiar tomadas de decisões gerenciais, ampliando seu leque de benefícios.

O estudo está assim organizado: a segunda seção discute o contexto da realidade abordada; a terceira, denominada Diagnóstico da Situação Problema, compreende o referencial teórico que sustenta a pesquisa, além de descrever o processo dos Concursos Públicos e dos PSS na Universidade e as funcionalidades do Software gerenciador dessas seleções; na quarta seção, nomeada Análise da Situação-problema, são descritos a caracterização da pesquisa e os procedimentos metodológicos, bem como o diagnóstico que analisou o material coletado, evidenciando os resultados obtidos; na sequência, a quinta seção traz a proposta de intervenção, alinhada à problemática levantada. Nas considerações finais, apresentam-se a síntese das contribuições desta pesquisa e sugestões para estudos futuros, incentivando a compreensão e a apropriação de conceitos de modo interdisciplinar, visando a avanços nas esferas teóricas e práticas.

\section{O Contexto e a Realidade Investigada}

A Universidade Federal do Pampa, lócus desta pesquisa, fez parte do Programa de apoio a Planos de Reestruturação e Expansão das Universidades Federais, o Reuni, alinhado à meta de ampliação da educação superior no Brasil, e teve sua lei de criação promulgada em 11/01/2008, com os objetivos de "minimizar o processo de estagnação econômica onde está inserida, pois a educação viabiliza o desenvolvimento regional, buscando ser um agente da definitiva incorporação da região ao mapa do desenvolvimento do Rio Grande do Sul", propiciando perspectivas à juventude de permanecer em sua região de origem, provendo as qualificações necessárias para impulsionar esse progresso, ao vislumbrar opções para o fortalecimento de uma sociedade cultural e economicamente desenvolvida (UNIPAMPA, 2017a).

Situada na região sul do Estado do Rio Grande do Sul, Brasil, tem, dentre as suas particularidades, a distribuição de suas unidades acadêmicas em 10 campi. Essa configuração pretendeu romper com a centralização territorial da educação superior no Brasil, promovendo a interiorização e a consolidação de projetos alternativos de desenvolvimento social, econômico e cultural, apropriado às necessidades regionais e locais frente à estagnação própria de regiões brasileiras periféricas, incluída, no diagnóstico da época, a região sul do RS (Marchioro et al., 2007).

A respeito das dimensões organizacionais da UNIPAMPA, Neiva (2015) sugere a implementação de efetivos mecanismos de integração e um eficaz sistema de comunicação para suprir fragilidades nas 
estratégias e nos instrumentos conformadores do caráter orgânico e articulado do modelo multicampi. Nesta lógica, sobre os desafios enfrentados por uma Instituição de Ensino Superior (IES) pública que adota a estrutura organizacional multicampi, os dados coletados por Nez (2016) indicaram a utilização das tecnologias enquanto principal solução citada para superação das distâncias geográficas entre os campi.

\section{Diagnóstico da Situação Problema}

O referencial teórico que instigou o diagnóstico e suportou a proposta de intervenção aborda pesquisas que envolvem a importância dos sistemas de informação e dos Softwares, em especial na administração pública brasileira, com foco na engenharia de Software e consequentemente no seu desenvolvimento e implantação, buscando valorizar o propósito de adequação da tecnologia às necessidades das tarefas dos usuários.

\section{Sistemas de informação, como inovações tecnológicas na administração pública brasileira}

As tecnologias e os sistemas de informação, segundo Davenport (2013), devem ser vistos como facilitadores do processo de inovação devido ao grande potencial em auxiliar as organizações a alcançarem significativas reduções de custos e tempo nos processos e substanciais melhorias na qualidade, na flexibilidade e nos níveis dos serviços prestados.

Em uma descrição do ponto de vista da funcionalidade, Bernus, Mertins e Schmidt (2006) consideram um sistema de informação como um sistema para coleta, processamento, armazenamento, recuperação e distribuição de informação dentro das organizações, e entre a organização e o ambiente em que está inserida.

Definição mais abrangente, descrita por Kanaane, Fiel e Ferreira, (2010), entendem os sistemas de informação formados por recursos tecnológicos, pela programação de sistemas e pela utilização desses sistemas por indivíduos e sociedade.

Essa interação é descrita por Sommerville (2011) ao descrever os sistemas sócio-técnicos, como aqueles que incluem sistemas técnicos, processos operacionais e pessoas, as quais usam e interagem com esse sistema, regidos, por políticas e regras organizacionais.

Nas organizações públicas brasileiras, repensa-se, cada vez mais, sobre o volume de dados presentes na organização, e sobre a necessidade de transformá-los em informações, as quais contribuam para a gestão do conhecimento com ênfase nos resultados, gestão essa ancorada em fatores como confidencialidade, integridade, disponibilidade e segurança (Kanaane, Fiel, \& Ferreira, 2010). Para os autores, à medida que a sociedade evolui, os processos de informação seriam reformatados e ajustados a fim de se adequarem aos modelos e processos organizacionais, acompanhando as rápidas mudanças tecnológicas.

As soluções em tecnologia de informação, sistemas de informação e Software têm se apresentado como formas de garantir a gestão do conhecimento, aperfeiçoar processos, eliminar rotinas que não agreguem valor, padronizar procedimentos e comunicar de forma abrangente a missão da organização. Segundo Laudon e Laudon (2010), tanto as tecnologias da informação quanto os sistemas de informação objetivam trazer para as organizações seis benefícios: sobrevivência, relacionamento estreito com clientes e fornecedores, novos produtos ou serviços, vantagem competitiva, excelência operacional e melhor tomada de decisões.

Ao pesquisarem a inovação na administração pública brasileira no período de 2006 a 2015, Pires, Prado, Ferreira e Rita (2016) observaram que, dentre as principais limitações identificadas estavam as tecnológicas, às quais se creditaram as barreiras ao baixo investimento em sistemas de informação mais 
eficientes. Das possibilidades de inovação apresentadas pelos autores, destacamos a adoção de novas tecnologias de informação e comunicação (TICS), objetivando prover a atualização rápida e descentralizada das informações, beneficiando processos decisórios e a opção por novos métodos de trabalho, proporcionando a melhoria da gestão do conhecimento.

Iniciativas pontuais nessa temática podem ser mencionadas, é o caso analisado por N. Silva, Jacobsen, Almeida e Olivo (2013), em que a introdução de um sistema de informação com vistas a maior rapidez na tramitação de documentos, transparência e eficiência na execução de processos administrativos (com a redução significativa do uso de papel) em uma Universidade Federal buscou inovar, técnica e radicalmente, conduzindo a novas práticas e técnicas de gestão. De Muylder, Nicholls, La Falce, Martins e Dias (2013), por sua vez, observaram uma ruptura de paradigma com a implantação de uma inovação tecnológica no serviço de controle tributário em um órgão público, correspondendo a inovações tanto em processo quanto em produto, este explícito pelo desenvolvimento de um novo Software.

\section{Soluções de software: desenvolvimento e aplicações}

De acordo com Pressman (2010), o Software se tornou uma tecnologia indispensável, dos negócios às ciências, permitindo a criação de novas tecnologias, o aprimoramento das existentes e o abandono de tecnologias mais antigas. Ainda, é o responsável pela entrega do produto mais importante de nossa época, a informação, ao transformar dados para serem úteis em um determinado contexto.

Aponta a tendência de substituição da figura do programador individual para a de um time de especialistas em Software, em que cada um focaliza em uma parte da tecnologia necessária à entrega de uma aplicação complexa. Como, por outro lado, as questões centrais para a construção desses sistemas não mudaram (por ex.: Por que não se consegue encontrar todos os erros antes da entrega dos Softwares aos clientes? Por que se gastam tanto tempo e esforços mantendo os programas existentes, ao invés de adquirir ou criar novos?), essas preocupações levam à adoção de práticas de Engenharia de Software (Pressman, 2010).

A Engenharia de Software, segundo conceituado por Sommerville (2011), dedica-se aos aspectos práticos de desenvolvimento e de entrega de Software para uso, podendo ser criado através do desenvolvimento de novos programas, da configuração de sistemas de Software genéricos ou da reutilização de um Software existente. As atividades genéricas em todos os processos de Software são: especificação - o que o sistema deve fazer e suas restrições; desenvolvimento - produção do sistema de Software; validação - verificação se o Software é o que o cliente deseja; evolução - mudança do Software em resposta às demandas.

Quanto aos atributos essenciais, o Software deve ser de fácil manutenção, confiável, eficiente e aceitável (pelos usuários para o qual foi projetado, em relação à sua usabilidade). Além disso, deve ser compatível com outros sistemas (Sommerville, 2011).

No tocante à confiabilidade, não se restringe ao Software, incluindo também o operador, pensando em reduzir a probabilidade de este cometer um erro. Defeitos de Software podem provocar situações que causem estresse no operador e levá-lo a cometer erros. O ambiente no qual um sistema é inserido tem efeito em sua confiabilidade (Sommerville, 2011).

Em Engenharia de Software no Gerenciamento de Projetos, uma metodologia é um conjunto estruturado de práticas, como: Material de Treinamento, Programas de educação formais, Planilhas e Diagramas. Abrangem muitas disciplinas, incluindo Gerenciamento de Projetos e suas fases, a saber: análise, projeto, codificação, teste e garantia da qualidade (Sommerville, 2011).

Portanto, o desenvolvimento e a implementação tem lugar de destaque nessas abordagens, procurando estruturar modelos de avaliação de Software e de sistemas de informação para essas etapas. Neste sentido, Yusof, Papazafeiropoulou, Paul e Stergioulas (2008), ao estruturarem um método de avaliação para um Sistema de Informação em Saúde, criaram um modelo para promover ajuste 
tecnológico, humano e organizacional. Concluíram que os usuários com atitudes e habilidades adequadas, juntamente com boa liderança, ambiente de TI amigável e boa comunicação, podem influenciar positivamente na adoção do sistema/Software, reduzindo problemas de adequação e resistências à aceitação de mudanças.

Cresswell, Bates e Sheikh (2013), ao detalharem dez considerações chave na implementação e na adoção bem-sucedida de uma TI, advertem sobre a importância do treinamento, pois os usuários tendem a ficar mais satisfeitos com as novas tecnologias do que aqueles não adequadamente treinados, o que creditam à falta de compreensão das capacidades do sistema, que pode ter como consequências a sua subutilização, ou até não ser utilizado. Alertam que, em muitos casos, as expectativas das organizações e dos usuários excedem o que é possível alcançar no curto prazo. O gerenciamento das expectativas se torna importante para evitar o desengajamento e as atitudes negativas. Advogam que um planejamento cuidadoso e uma avaliação crítica e contínua do progresso são centrais para a implementação, sugerindo a perspectiva do ciclo de vida de tecnologias: estabelecimento do que precisa ser mudado; escolha do sistema alvo das mudanças; planejamento (estratégia de implementação, de infraestrutura e de treinamento); manutenção e avaliação constantes.

A teoria Task Technology Fit (TTF), em tradução livre, Teoria de Ajuste de Tecnologia e Tarefas, concebida por Goodhue e Thompson (1995), sustenta que a Tecnologia em Informação (TI) tem maior probabilidade de impactar positivamente no desempenho individual do usuário se as capacidades da tecnologia corresponderem às tarefas que o usuário deve executar. A medida de ajuste de tarefatecnologia consiste em oito fatores: qualidade, localização, autorização, compatibilidade, facilidade de uso / treinamento, oportunidade de produção, confiabilidade de sistemas e relacionamento com os usuários. Embora o modelo de Goodhue e Thompson (1995) funcione no nível de análise individual, Zigurs e Buckland (1998) apresentam um modelo análogo operando no nível de grupo. Em um processo de revisão da literatura, Furneaux (2012) identificou 81 artigos, no período de 1995 a 2008, que incorporaram a Teoria TTF de maneira substantiva, tanto para descrever aplicações quanto para desenvolvimentos, sendo que os últimos três anos da análise caracterizaram um notável aumento em seu uso, com 28 das publicações.

No Brasil, uma pesquisa que convergiu o modelo TTF com o modelo Technology Acceptance Model (TAM) foi desenvolvida por Tolentino, Tolentino, Gonçalves e Souki (2007), ao proporem um modelo integrador TFT-TAM no cenário brasileiro, contribuindo com aspectos pertinentes à implementação de sistemas de informação nas organizações, ao observarem o expressivo impacto da utilidade no desempenho dos usuários. Pesquisa que aplicou uma versão integrada dos modelos TFTTAM foi a de Perácio (2017), que a utilizou para avaliar um sistema de informação para o controle de afastamentos na UFMG. Dentre as hipóteses testadas, as que apresentaram maior significância explicativa demonstraram que os usuários tinham a intenção de continuar utilizando o sistema porque percebiam a sua utilidade, conquanto também adequado às suas tarefas e de fácil utilização.

Por esse ângulo, estudos têm buscado aprimorar modelos de desenvolvimento de Software que tenham, no ser humano, elemento central, e, na tecnologia, vetores, para servir às exigências e às características humanas.

A Metodologia Ágil, de acordo com Darwish e Rizk (2015), proporciona maior flexibilidade aos processos de desenvolvimento de Software, pois prevê entregas rápidas, fases simples, preocupação com mudanças nos requerimentos e forte comunicação entre desenvolvedores e clientes. Os autores propuseram um framework dos fatores de sucesso em projetos ágeis, nos quais os classificaram em cinco dimensões: organizacional, pessoas, processos, projeto, técnico. Em resumo, temos que uma cultura de apoio da alta gestão a um time de desenvolvedores capazes (e do tamanho apropriado) operando com ferramentas e infraestrutura necessárias, tecnologia familiar, em um ambiente que envolva os usuários numa comunicação efetiva e com feedbacks e testes constantes, guiados por objetivos, requerimentos e especificações claros (e com mínimas mudanças), sem esquecer os prazos realistas, reúne as características essenciais do modelo. 
Pesquisa de Roses, Windmöller e Carmo (2016) analisou as condições favoráveis na adoção do método ágil ou tradicional no desenvolvimento de Software, apontando que a adaptação de um método deve ser baseada na realidade dos processos organizacionais e de melhores práticas. Para isso, compararam-se as perspectivas (tradicionais e ágeis) associadas a dimensões baseadas na teoria da engenharia de Software: conhecimento, administração e processos. A dimensão do conhecimento analisa a forma como a informação é exibida aos envolvidos na área de TI, refletindo no conhecimento adquirido e percebido. Na dimensão administrativa, os estilos de liderança na área de TI baseados em pessoas e criatividade são mais adequados para lidar com a imprevisibilidade. Já na dimensão de processos, o número de pessoas que trabalham em um projeto, o domínio da aplicação, a criticalidade e a capacidade de inovação determinam quais partes dos métodos a organização escolherá.

Propõem então que a conformidade das organizações com essas dimensões não só ajuda a escolher quais métodos são mais adequados à situação da organização, mas também se partes de métodos distintos podem ser combinadas para criar um método híbrido, que se adequaria a uma determinada organização (Roses, Windmöller, \& Carmo, 2016).

As práticas de alinhamento e recombinações de métodos em busca por melhor adequação pode ser compreendida na argumentação de Clarke, O’Connor e Leavy (2016) para os quais tanto os processos de Software quanto o contexto operativo devem ser considerados complexos. Na Teoria da Complexidade, múltiplos agentes interagem em uma multiplicidade de formas, sendo os resultados do sistema não determinísticos (o comportamento do sistema é especialmente dependente dos operadores humanos). O desafio de se harmonizar um processo de Software com o seu contexto deve ser enfrentado através da modelagem de Software, que seria capaz de avaliar as forças das inter-relações entre as entidades em um sistema complexo, salientando os benefícios das abordagens adaptativas para os desenvolvimentos de Softwares.

Ainda sobre a questão do contexto, Tonelli, Zambalde, Brito e Bermejo (2016) estudaram as ambidesteridades (no sentido de dupla capacidade de resposta frente às operações correntes e as perspectivas futuras) dentro do processo de inovação em Software, tentando compreender de que forma se organizar para atender enfoques simultâneos e aparentemente contraditórios, balanceando um contexto de foco excessivo no aproveitamento de capacidades atuais e um contexto de mudança em direção à inovação. Como exemplos, tem-se que: (a) aperfeiçoar processos de desenvolvimento atuais e, ao mesmo tempo, adaptar tais processos para lidar com necessidades mutantes de clientes; (b) aproveitar capacidades já existentes em termos de tecnologias e de base de clientes e, ao mesmo tempo, explorar novas oportunidades tecnológicas e novos nichos de mercado (Napier, Mathiassen, \& Robey, 2011).

\section{Soluções de software na administração pública brasileira}

A partir do século XXI, a Administração Pública Federal brasileira tem buscado, ao mesmo tempo, tanto acompanhar quanto protagonizar a adoção de evoluções tecnológicas associadas aos meios eletrônico e digital. As ações de governo digital começaram a ser estruturadas no início da década de 2000 sob a denominação de governo eletrônico (e-Gov) e possuem a finalidade de priorizar o uso das tecnologias da informação e da comunicação (TIC) para democratizar o acesso à informação ( Ministério do Planejamento, Orçamento e Gestão, 2016).

Em pesquisa de Cepik et al. (2009) foram avaliados o desempenho de 195 políticas de governo eletrônico, por meio do Índice de Qualidade de e-Serviços Governamentais (IQUES). Utilizando grupos de indicadores divididos em: e-Atendimento, Facilidade de Uso e Confiabilidade, concluíram, entre outras coisas, que o incremento dos e-serviços governamentais deve ser acompanhado pelo constante desenvolvimento dos portais, com o intuito de simplificar o uso e o acesso dos cidadãos.

Dentre as iniciativas, destacamos quatro delas, de fomento a soluções de Software, as quais podem ser visualizadas na Tabela 1. 
Tabela 1

Fomento a Soluções de Software pelo Governo Federal Brasileiro

\begin{tabular}{ll}
\hline Iniciativa & Detalhamento \\
\hline ePING $^{1}$ & A arquitetura ePING (Padrões de Interoperabilidade de Governo Eletrônico) é concebida \\
& como uma estrutura básica para a estratégia e-Gov, aplicada aos órgãos e às entidades \\
& integrantes do Sistema de Administração dos Recursos de Tecnologia da Informação \\
& (SISP). Permite racionalizar investimentos em TIC, por meio de compartilhamento, reuso \\
& e intercâmbio de recursos tecnológicos. A interoperabilidade pode ser entendida como uma \\
& característica que se refira à capacidade de diversos sistemas e organizações trabalharem \\
& em conjunto, de modo a garantir que pessoas, organizações e sistemas interajam para trocar \\
& informações de maneira eficaz e eficiente.
\end{tabular}

Guia de Processo Aborda não só as atividades ligadas ao desenvolvimento de Software como também de Software para o relacionadas ao planejamento dos recursos necessários ao ambiente necessário para o seu SISP $^{2} \quad$ funcionamento. O processo de Software tem seis fases (concepção e alinhamento estratégico, especificação e dimensionamento, estratégia de desenvolvimento, desenvolvimento, implantação e estabilização, e sustentação e evolução) e oito eixos (alinhamento estratégico, gestão de projetos, produção colaborativa, gestão de segurança, engenharia de Software, gestão da contratação, gestão de infraestrutura e gestão de sustentação).

Software Livre ${ }^{3} \quad$ Opção estratégica do Governo Federal para reduzir custos, ampliar a concorrência, gerar empregos e desenvolver o conhecimento e a inteligência do país na área. Para incentivar o uso do Software livre, o Estado promove ações voltadas para o uso de padrões abertos, o licenciamento livre dos Softwares e a formação de comunidades interessadas no tema. Inclusive, mantém um Comitê Técnico de Implementação de Software Livre, com mais de 40 comunidades virtuais que disseminem conhecimento e ações em prol do Software livre.

Software Público Tipo específico de Software livre que atende às necessidades de modernização da Brasileiro $^{4} \quad$ administração pública de qualquer dos Poderes da União, dos Estados, do Distrito Federal e dos Municípios e é compartilhado sem ônus no Portal do Software Público Brasileiro, resultando na economia de recursos públicos e constituindo um recurso benéfico para a administração pública e para a sociedade.

Nota. Fonte: ${ }^{1}$ Ministério do Planejamento, Orçamento e Gestão. Secretaria de Tecnologia da Informação. Departamento do Governo Digital. (2017). gov.br ePING padrões de interoperabilidade de Governo Eletrônico: Documento de referência. Recuperado de https://www.governoeletronico.gov.br/documentos-e-arquivos/e-PING_v2017_20161221.pdf; ${ }^{2}$ Ministério do Planejamento, Orçamento e Gestão. Secretaria de Logística e Tecnologia da Informação. (2012). Processo de software para o SISP: versão 1.O. Brasília: MP. Recuperado de http://www.sisp.gov.br/pswsisp/wiki/download/file/guiaPsw; ${ }^{3} \mathrm{Governo}$ Eletrônico. Ministério do Planejamento, Orçamento e Gestão. (2016, julho 25). Implementação de software livre. Recuperado 4 fevereiro, 2017, de https://www.governodigital.gov.br/sobre-o-programa/estrutura-governo-eletronico/comitestecnicos/implementacao-de-software-livre; ${ }^{4}$ Software Público Brasileiro. Ministério do Planejamento, Orçamento e Gestão. (2014, dezembro 4). O que é o software público. Recuperado 3 abril, 2017, de https://softwarepublico.gov.br/social/spb/o-quee-o-software-publico

Existem soluções ainda em estágio inicial em termos do alcance de sua utilização no serviço público brasileiro, como o Software as a Service (SaaS), em tradução livre: Software como serviço. Na definição de Mell e Grance (2011), é o modelo que fornece ao consumidor a capacidade de utilizar os aplicativos disponibilizados pelo provedor em sua própria infraestrutura, acessíveis a partir de diversos dispositivos, por meio de uma interface simples, como um navegador.

O trabalho de Evangelista e Souza (2016) propôs um modelo para a avaliação da capacidade da área de TI de uma organização da APF de contratar e operar Software como serviço (SaaS) disponibilizado em um provedor de nuvem pública. No geral, as organizações pesquisadas demonstraram pouca afinidade com computação em nuvem.

Em 2016, foi desenvolvida a Estratégia de Governança Digital (EGD), que pretende orientar e integrar as iniciativas relativas à governança digital na administração direta e na indireta do Poder Executivo Federal, contribuindo para beneficiar a sociedade por meio da expansão do acesso às 
informações governamentais, da melhoria dos serviços públicos digitais e da ampliação da participação social (Ministério do Planejamento, Orçamento e Gestão, 2016). No plano, entre os principais desafios a serem enfrentados para o aprimoramento e a efetividade das ações de governança digital, destacamos aqueles em sintonia com o diagnóstico em pauta e com potencial de aplicabilidade em diversos níveis governamentais: (a) integrar processos, sistemas e serviços, reduzindo as soluções em silos; (b) ampliar o compartilhamento de sistemas, serviços e dados, estimulando a integração e a interoperabilidade entre sistemas transversais e de informações do governo; (c) orquestrar o reuso de sistemas administrativos, reduzindo a duplicidade de esforços e a geração de informações fragmentadas e não padronizadas, e o desperdício de recursos e tempo (Ministério do Planejamento, Orçamento e Gestão, 2016).

Atualmente, o Processo Eletrônico Nacional (PEN), uma iniciativa conjunta de órgãos e entidades da administração pública brasileira, que promove infraestrutura pública de processos e documentos administrativos eletrônicos em um mesmo ambiente virtual, principalmente por meio da entrega do SEI (Sistema Eletrônico de Informações), desenvolvido pelo Tribunal Regional Federal da $4^{\text {a }}$ Região, com pretensos ganhos em agilidade, produtividade, transparência, satisfação do usuário e redução de custos, está em fase de implementação em diversos órgãos, inclusive na UNIPAMPA (Ministério do Planejamento, Orçamento e Gestão, n.d.). O Decreto n ${ }^{\circ} 8.539$, de 08 de outubro de 2015, previu até 2 anos para que órgãos e entidades implementassem o meio eletrônico para a realização de processos administrativos, acrescidos de mais 1 ano para os que já utilizam desse meio adaptarem-se ao regramento.

\section{Os concursos públicos e os processos seletivos simplificados para docentes na UNIPAMPA e o software atual}

O macroprocesso de suprimento de recursos humanos ou de admissão de pessoal no setor público envolve quatro fases bem definidas, que podem ser visualizadas como processos específicos: recrutamento, seleção, admissão e registro (Bergue, 2010). Os concursos e as seleções, aqui estudados, compreendem as etapas de recrutamento e seleção.

Os produtos da Divisão de Concursos estão divididos em dois processos: (a) Concursos Públicos, destinados ao provimento do cargo de professor da carreira do magistério superior e do cargo isolado de professor titular-livre do magistério superior, conforme Resolução ${ }^{\circ}$ 82/2014; e (b) Processos Seletivos Simplificados (PSS), destinados à contratação de docentes substitutos, conforme Resolução $n^{\circ}$ 117/2015. Em termos de suas etapas, assemelham-se, porém surgem particularidades quando detalhamos as provas e as publicações dos resultados. Assim tem-se, de forma genérica para ambos os processos: publicação do Edital, inscrições, homologação das inscrições, abertura do Certame, aplicação das provas e sessão pública de divulgação de resultado (UNIPAMPA, 2014, 2015).

Em relação às provas, as modalidades são escrita, didática, de defesa do memorial descritivo no Concurso e de entrevista no PSS, e de títulos. Além das diferenças de pesos nos cálculos das provas e em quais são as etapas ou modalidades consideradas classificatórias e/ou eliminatórias, conforme consta nas Resoluções, enquanto no Concurso todas as quatro provas são de aplicação obrigatória, no PSS somente a prova didática é de natureza obrigatória, ficando a critério do campus proponente, desde que conste no Edital de Abertura, a realização das outras modalidades de provas (UNIPAMPA, 2014, 2015).

Sobre os resultados, no PSS a Divisão de Concursos publica o resultado preliminar depois de findas as etapas a cargo dos Campi, abrindo-se prazo para interposição de recursos antes da homologação do resultado final publicado no Diário Oficial da União (UNIPAMPA, 2015). Assim, tornam-se imperativas a celeridade e a confiabilidade na conferência da documentação.

Como os principais objetivos do processo são a execução, o acompanhamento das etapas e o controle dos dados provenientes de cada seleção de concurso ou processo seletivo, sentiu-se a necessidade de uma ferramenta que auxiliasse, de forma efetiva, a execução das provas, garantindo que os registros fossem padronizados e pudessem ser consultados, além de permitir que dados de uma determinada etapa pudessem ser replicados para outras subsequentes, sem a necessidade de se repetir a digitação, reduzindo-se parte do esforço operacional. 
Desse modo, foi desenvolvido endogenamente o Software Gerenciador de Concursos Públicos. De acordo com seu Manual de Utilização Rápida, tem como objetivos:(a) auxiliar a banca examinadora na elaboração dos documentos relativos aos concursos, como atas, planilhas, listas de presença, pareceres; (b) uniformizar os procedimentos nos diversos concursos que acontecem em paralelo na Instituição; (c) minimizar erros de digitação; agilizar os procedimentos para que não ocorram atrasos que possam comprometer a homologação do concurso no prazo estipulado; (d) consolidar a UNIPAMPA como uma universidade ágil, moderna e eficiente (UNIPAMPA, 2013). O Software é operado por servidor público federal, designado membro de uma das dez (10) Comissões Locais de Concursos, que deve contar com, no mínimo, cinco integrantes.

Acerca das funcionalidades do Software, cabe ressaltar sua capacidade de gerar documentos (em Rich Text Format) a partir de modelos padrão pré-estabelecidos (que podem ser editados), dispostos ao usuário na ordem dos atos, dentro das etapas possíveis de aplicação das provas (Abertura, Prova Escrita, Prova de Títulos, Prova Didática, Prova de Defesa de Memorial de Trajetória Acadêmica - ou Entrevista - e Sessão de Divulgação dos Resultados). Poder visualizar o fluxo completo, além dos documentos que já foram gerados e encontram-se armazenados, divididos por tipo, facilita sobremaneira o trabalho da banca examinadora, corresponsável pela gestão do tempo junto as CLC's, podendo se concentrar mais em sua função julgadora. Outras funcionalidades de destaque são o cálculo automático das notas da prova de títulos e o cálculo automático das médias finais dos candidatos.

\section{Análise da Situação-Problema}

Para Bergue (2010), as provas são o elemento central do processo de seleção. Neste aspecto, o perceptível número de erratas e algumas reclamações pontuais sobre o Software motivaram a melhor compreensão dos problemas, para que se projetassem as soluções apropriadas.

A pesquisa desempenhada empregou uma abordagem qualitativa, qual seja com o desejo de obter um profundo entendimento de uma situação por meio de um conjunto de técnicas interpretativas, enquanto, do ponto de vista de sua natureza, a pesquisa é aplicada, pois objetiva construir soluções práticas na resolução de problemas em um contexto definido (Cooper \& Schindler, 2016).

Quanto aos procedimentos técnicos, os meios de investigação adotados foram as pesquisas bibliográficas, documental (física e digital) e a observação participante. De acordo com Cooper e Schindler (2016), a pesquisa bibliográfica é desenvolvida com base em fontes secundárias, sendo esses documentos já publicados (livros ou artigos científicos), enquanto a pesquisa documental utiliza fontes primárias, material bruto que ainda não recebeu uma interpretação, que pode envolver a busca em dados internos para entender o problema gerencial ou para ideias de solução. Sobre a observação participante, entendem como um método flexível para lidar com situações habituais em que os membros das comunidades se encontram envolvidos, e para acessar dados que a comunidade ou grupo costuma ignorar por julgar não relevantes ou muito comuns, possibilitando coletar dados originais no momento em que ocorrem (Cooper \& Schindler, 2016).

Para serem identificados os fatores que levaram aos erros nos registros, acrescentando etapas corretivas anteriores à publicação dos resultados, buscou-se aprofundar na análise das fontes que indicaram inicialmente os problemas em questão. Foram selecionadas as Erratas, que são correções tipográficas anexadas em publicações em geral (livros, manuais, artigos, dissertações, etc.), e são caracterizadas pelo uso de texto no padrão "onde se lê" (para o item que se deseja modificar) / "leia-se" (para o item corrigido), acrescidos das devidas identificação e assinatura dos responsáveis (SciELO, 2017). No caso dos concursos, tais documentos, elaborados pelas Comissões Locais de Concursos são inseridos, quando necessários, ao final dos processos físicos, que guardam a documentação relativa a cada certame em particular. A escolha configurou um novo uso desse material, ressignificado estrategicamente para subsidiar a interpretação da situação aventada. 
Foram 99 erratas encontradas no período de janeiro de 2015 a dezembro de 2016. Os equívocos foram classificados conforme duas categorias, com três subcategorias em cada.

Sobre a definição das categorias, as mesmas foram inspiradas na previsão dos impactos dos defeitos constantes da IEEE Standard Classification for Software Anomalies - IEEE 1044-2009. No entanto, ressalvamos ter sido adaptadas para somente duas categorias principais (ao invés das seis possíveis): a primeira, de modo a destacar aqueles com alto grau de impacto por potencialmente interferirem diretamente nos resultados, enquanto a segunda concentrou os incidentes com baixo potencial de impacto na eficácia dos concursos. A Categoria 1 trata dos Equívocos em Notas, ou seja, cálculos incorretos, pesos não ajustados, escolha do processo distinto (i.e., selecionar no Software que irá ocorrer um Concurso quando na verdade se trata de um Processo Seletivo, e vice-versa, o que ocasiona diferenças nos cálculos devido às regras próprias de pesos e cálculos). A Categoria 2 trata dos Equívocos nos demais documentos que não envolvem notas, como datas e horários divergentes e nomes digitados erroneamente, em atas, listas, etc.

As incidências foram registradas conforme a presença ou não de determinado equívoco na errata, isto é, se houve a ocorrência, independente do quantitativo encontrado. Os resultados podem ser visualizados no Tabela 2.

Tabela 2

\section{Categorização dos Equívocos}

\begin{tabular}{ccccc}
\hline Natureza dos Equívocos & $\begin{array}{c}\text { Categoria 1: } \\
\text { Equívocos em } \\
\text { Notas }\end{array}$ & $\begin{array}{c}\text { Categoria 2: } \\
\text { Equívocos nos } \\
\text { demais } \\
\text { documentos }\end{array}$ \\
\hline & A $\quad \begin{array}{l}\text { Erros de digitação via reprodução de dados já publicados e/ou } \\
\text { armazenados em outros sistemas de informação ou Softwares } \\
\text { da Instituição* }\end{array}$ & 05 & 10 \\
\cline { 2 - 5 } & B $\quad \begin{array}{l}\text { Erros de digitação de dados novos, gerados durante o decorrer } \\
\text { das seleções (tanto oriundos da atuação de membros das } \\
\text { comissões quanto da banca examinadora) }\end{array}$ & 27 & 47 \\
\cline { 2 - 5 } & C & $\begin{array}{l}\text { Falhas de Software (parametrização, versão desatualizada, } \\
\text { desajuste com as resoluções, etc.) }\end{array}$ & 10 & 37 \\
\hline TOTAL & & 42 & 94 \\
\hline
\end{tabular}

Nota. Fonte: Elaborado pelos autores.

* Dados já publicados ou armazenados incluem área de conhecimento, modalidades das provas com os respectivos pesos nos cálculos, programa das provas, além de nome dos candidatos, da banca examinadora.

A Tabela 2 demonstra que a incidência de equívocos relacionados à categoria 2 (94) foi superior à da categoria 1 (42), o que demonstra que erros de menor impacto aconteceram com maior frequência. Adentrando nos detalhes das subcategorias $\mathbf{A}, \mathbf{B}$ e $\mathbf{C}$, de ambas as categorias, tem-se que os erros de digitação de dados novos, gerados no decorrer das seleções, foram os mais recorrentes, representando aproximadamente $64 \%$ das incidências na Categoria 1 e $50 \%$ na Categoria 2. No entanto, é importante ressaltar que, nos casos da Categoria 1, a maior parte destes estavam relacionados com cálculos manuais incorretos que, após conferência, foram sanados, enquanto na Categoria 2, em sua maioria, referem-se a datas ou horários registrados com alguma desconformidade, igualmente sanados.

Por outro lado, é importante citar que $24 \%$ e $39 \%$, respectivamente, das incidências nas erratas de equívocos relacionadas às falhas de Software, nas Categorias 1 e 2, que representam 35\% do total quando relativizadas em conjunto, demonstram que o acerto de parametrização, o alinhamento fino com as resoluções e a utilização das versões adequadas do Software teriam potencial para terem evitado por volta de $1 / 3$ das necessidades de erratas. 
Já nos tipos de equívocos da subcategoria $\mathbf{A}$, os números nos mostram que, se houvesse a integração de sistemas para compartilhamento de dados já registrados, o retrabalho evitado poderia ter reduzido em torno de $12 \%$ (Categoria 1 ) e $11 \%$ (Categoria 2).

Deste modo, os problemas identificados e as situações a serem aprimoradas foram relacionados ao impacto que causam nos equívocos da Tabela 3 , dispostos como A, B e C.

Tabela 3

\section{Relação dos Problemas Identificados com as Subcategorias da Tabela 2}

\section{Detalhes das situações evidenciadas}

\section{Subcategorias \\ de equívocos}

A

Necessidade de digitar dados já publicados (Dados do Edital de Abertura, por exemplo) ou armazenados em outros Sistemas de Informação/Softwares da própria instituição (dados dos candidatos, por exemplo). Para iniciar o procedimento no Software, gastando-se tempo, aumentando as chances de erros de digitação.

\begin{tabular}{lc}
\hline Alto número de inserções manuais & A e B \\
\hline $\begin{array}{l}\text { Necessidade de se conferir todos os documentos do concurso, por conta do receio de erros de } \\
\text { digitação e de cálculos, exigindo tempo de conferência em demasia por parte dos técnicos da }\end{array}$ & B \\
Divisão de Concursos. & \\
\hline
\end{tabular}

Nível de compreensão sobre as funcionalidades e as limitações do Software não são os mesmos entre as diferentes Unidades (e provavelmente não é o mesmo dentre os membros de cada Comissão, dadas às dúvidas verificadas).

Os resultados de determinadas etapas nas provas (didática, entrevista, títulos) não alimentaram automaticamente os valores para o cálculo do resultado final, exigindo a inserção manual desses dados.

Dependência do programador que desenvolveu o Software para todas as ações de atualização e manutenção do Software.

\begin{tabular}{ll}
\hline Acesso ao Software não é restrito por usuário. & $\mathrm{C}$ \\
\hline Diferentes versões do Software sendo utilizadas em paralelo. & $\mathrm{C}$ \\
\hline $\begin{array}{l}\text { Software hospedado em um computador. Quando este precisou ser levado para manutenção, o } \\
\text { Software ficou sem proceder com atualizações. }\end{array}$ & $\mathrm{C}$ \\
\hline
\end{tabular}

Falta de funcionalidades para lidar com itens da resolução, como, por exemplo, os descontos atribuídos a candidatos que não atentarem ao tempo estipulado na prova didática, e falta de inclusão de alguns textos específicos de cada seleção (Concurso ou PSS); como as atas e demais documentos gerados são modelos, a especificidade de cada seleção deve ser alterada. Também é possível incluir informações relevantes ou excluir as inadequadas. A revisão das atas antes da impressão, fundamental, não ocorreu ou não evitou os equívocos.

\begin{tabular}{ll}
\hline $\begin{array}{l}\text { Ausência de suporte formal ao Software dentro da Estrutura Organizacional da Universidade, } \\
\text { englobando os quesitos de infraestrutura, técnicos e de programação. }\end{array}$ & A, B e C \\
\hline $\begin{array}{l}\text { A Divisão de Concursos não tem acesso aos dados digitais das seleções no Software, o que não } \\
\text { he permite fazer conferências via sistema. }\end{array}$ & A, B e C \\
\hline $\begin{array}{l}\text { A Divisão de Concursos e a Gestão não tem acesso aos dados digitais das seleções, o que não } \\
\text { lhe permite gerar relatórios e indicadores de desempenho via sistema. }\end{array}$ & A, B e C \\
\hline
\end{tabular}

Nota. Fonte: Elaborada pelos autores.

Paralelamente à análise do conteúdo das Erratas, verificaram-se os e-mails de solicitação de cada uma das erratas em análise, dando atenção às respostas de membros das Comissões Locais que tratavam especificadamente sobre as suas percepções a respeito dos erros nos registros encontrados nas conferências. Em resumo, os e-mails versaram sobre: a necessidade de ajuste de algum item do Software 
em relação ao que constam nas resoluções; a constatação de ser preciso confeccionar documentos não presentes no Software; e o Software não ter calculado automaticamente algumas das médias resultantes.

Durante a observação e o acompanhamento do processo de provas e títulos, aconteceu um fato que chamou a atenção dos pesquisadores. Em determinada situação, recebemos contatos das Unidades de que o Software não estava se atualizando automaticamente para sua versão mais recente. Para solucionar a questão, foi preciso recorrer ao desenvolvedor inicial do Software (que não era membro dos órgãos de apoio e suporte as TIC's), ao invés do atendimento do Setor de TI da Instituição. Assim, identificaram-se uma lacuna e uma oportunidade de melhoria, devidamente incluídas no diagnóstico.

Concluído o diagnóstico inicial, prosseguiu-se à construção de uma proposta de intervenção com base nas evidências auferidas e no referencial teórico.

\section{Proposta de Intervenção}

No caso ora em questão, a proposta foi baseada em melhorias relacionadas diretamente ao Software, mas mantendo o usuário como figura central. A proposta de intervenção foi desenhada com os seguintes objetivos norteadores:

- Reduzir sensivelmente o tempo de execução das provas e seleções de concursos públicos e PSS;

Reduzir também significativamente o tempo e as ações envolvidas na etapa de conferência da documentação dos concursos públicos e PSS;

- Garantir maior segurança e confiabilidade na execução das provas e, consequentemente, à documentação resultante;

- Contribuir para o estabelecimento de uma cultura organizacional propícia para detectar-se e propor a correção dos desperdícios e procedimentos equivocados, principalmente antecipando-se a essas ocorrências.

No que se refere à redução sensível no tempo de execução das provas, faz-se oportuno esclarecer de que forma se espera que aconteça. Como a duração total das etapas não é estabelecida pelo edital que rege os concursos e seleções, tendo em vista oscilar conforme o número de participantes, o número de provas aplicadas e a ocorrência de recursos interpostos pelos candidatos, o tempo gasto comparado de uma seleção para outra pode diferir em questão de horas, ou, até mesmo, dias. No entanto, existem ações comuns às seleções passíveis de se tornarem mais eficientes, relacionadas à eliminação de retrabalhos nas etapas de preparação e à abertura dos certames por conta da integração de dados pregressos (da banca de examinadores, dos candidatos, dos temas das provas, etc.), o aperfeiçoamento da automatização do transporte de dados de uma etapa à outra, sobretudo relativos aos cálculos aritméticos das notas, enfim, ações detalhadas nesta proposta que podem gerar a divulgação mais célere dos resultados parciais aos participantes.

Portanto, quanto ao Software e à sua interação com a Divisão de Concursos e as CLC's, propõese um conjunto de medidas objetivando sanar as dificuldades e as limitações diagnosticadas na utilização e na gestão do Software (planejamento, desenvolvimento, revisão, atualização e manutenção), refletindo o conjunto de princípios absorvidos da revisão teórica, conforme a Tabela 4. 
Tabela 4

Proposta de Melhorias - Atividades e Benefícios

\begin{tabular}{lcll}
\hline Etapas (fases) & $\mathbf{N}^{\mathbf{0}}$ & Atividades & Benefícios (ganhos) esperados \\
\hline $\begin{array}{l}\text { Planejamento / } \\
\text { Preparação }\end{array}$ & 1 & $\begin{array}{l}\text { Mapear os processos das áreas } \\
\text { requisitantes (junto aà Divisão } \\
\text { de Concursos e CLC's). }\end{array}$ & $\begin{array}{l}\text { Concebe aos analistas de TI a oportunidade de } \\
\text { melhor compreensão dos processos da área } \\
\text { requisitante na qual a solução será implantada, } \\
\text { considerando as interações que acontecem entre } \\
\text { esta e os atores externos envolvidos. }\end{array}$ \\
\hline
\end{tabular}

2 Levantar a demanda dos Permite registrar a percepção dos usuários a usuários e identificar os respeito dos pontos positivos e negativos na requisitos (a partir de utilização do Software atual e as expectativas entrevistas, consultas, com as atualizações vindouras. pesquisas, entre outras formas de coleta e registro).

3 Análise de viabilidade técnica Identificam-se as ideias mais viáveis do ponto de dos requisitos com refinamento vista humano e tecnológico, de modo a guiar o e detalhamento. desenvolvimento do Software.

4 Validação do Documento de Além de promover o alinhamento e a Requisitos gerado junto aos coparticipação no processo, colabora com a envolvidos. questão de cuidar para que as expectativas dos usuários se deem em bases realistas.

5 Reuniões para definição do escopo do projeto, bem como do Cronograma de execução das atividades subsequentes, junto aos desenvolvedores.

As reuniões devem contar com a participação dos gestores das áreas impactadas (Divisão de Concursos e da Diretoria de Tecnologia da Informação), de modo a obter o suporte direto da média gestão e o pretenso alinhamento com a alta gestão.

\begin{tabular}{lcll}
\hline $\begin{array}{l}\text { Desenvolvimento } \\
\text { (Fase Corretiva) }\end{array}$ & 6 & $\begin{array}{l}\text { Definir as parametrizações } \\
\text { emergenciais, desenvolvendo- } \\
\text { as de modo a ajustá-las aos } \\
\text { procedimentos e resoluções. }\end{array}$ & $\begin{array}{l}\text { Trata-se de lidar com correções nas } \\
\text { parametrizações de modelos de documentos, os } \\
\text { quais, sem esses ajustes, necessitam ser alterados } \\
\text { manualmente; portanto, há a redução na chance } \\
\text { de equívocos. }\end{array}$ \\
\hline
\end{tabular}

7 Criar Casos de teste/protótipos. Trata-se de disponibilizar tanto o ambiente quanto os casos de teste (o mais próximo da realidade possível) para as etapas subsequentes.

8 Realizar testes de usabilidade Permite aos usuários experimentação prévia para (aceitação). checar as adequações às tarefas e a facilidade de uso, gerando os respectivos feedbacks.

9 Realizar testes de sistemas Simular em ambiente de testes os impactos das (integração). atualizações no sistema, evitando previamente os efeitos indesejados.

10 Gerar os relatórios dos testes Registros importantes para guiar os desenvolvedores na realização de ajustes, caso necessário, quanto às dificuldades e às facilidades experimentadas em termos de usabilidade das alterações.

11 Efetuar ajustes e correções pré- Diminui as chances de erros serem apontados implementação. após liberação para uso. 
Tabela 4 (continuação)

\begin{tabular}{llll}
\hline Etapas (fases) & $\mathbf{N}^{\mathbf{0}}$ & Atividades & Benefícios (ganhos) esperados \\
\hline $\begin{array}{lll}\text { Desenvolvimento } \\
\text { (Fase Corretiva) }\end{array}$ & 12 & $\begin{array}{l}\text { Implementar as alterações à } \\
\text { produção. }\end{array}$ & $\begin{array}{l}\text { Deve-se cuidar o timing das atualizações para } \\
\text { não prejudicar seleções em andamento, por conta } \\
\text { de serem realizadas no ambiente produtivo, para }\end{array}$ \\
& & & $\begin{array}{l}\text { que os benefícios das correções não sejam } \\
\text { suplantados por desconfortos decorrentes da } \\
\text { implementação. }\end{array}$ \\
& & & \\
& &
\end{tabular}

13 Avaliar a eficácia e a efetividade das soluções aplicadas (entrevistas, questionários).

\section{Desenvolvimento (Fase adaptativa- evolutiva)}

Controle das ações e aferição da satisfação dos usuários.
14 Realizar a integração do Software ao portfólio institucional.

\begin{abstract}
Além de contar com a infraestrutura física, técnica e de pessoal do DTIC, tal integração permite a visualização de estratégias evolutivas, além daquelas corretivas e adaptativas. Para ser efetivada, um caminho promissor manifesta-se na análise da viabilidade de o Software ser internalizado como um módulo do sistema que gere os Recursos Institucionais.
\end{abstract}

15 Promover o compartilhamento Garantia da confiabilidade das informações e de informações entre o Software e o sistema que contém dados das seleções e processa as inscrições na UNIPAMPA. ganho de tempo durante a execução dos concursos.

Reduzir o retrabalho da digitação de dados já publicados e/ou armazenados em outros sistemas institucionais. Carregar automaticamente os dados da seleção, como os nomes dos candidatos, da banca examinadora, o programa das provas e as modalidades escolhidas, com os respectivos pesos, definidos em Edital de abertura.

16 Desenvolver novas Espera-se, entre os ganhos: que o Software funcionalidades para durante a execução das provas

forneça mensagem informativa sobre quais os valores esperados em determinado momento de inserção de dados; preenchimento automático da data do dia nos documentos, conforme checagem junto ao sistema operacional; criação de campos para incluir e calcular eventuais descontos aos candidatos por descumprirem o tempo estipulado da prova didática; prepará-lo para realizar todos os cálculos, ficando a cargo do operador do sistema somente a inclusão de dados primários.

17 Desenvolvimento de novas Temos as seguintes: i) Base de dados unificada, funcionalidades para permitir a hoje dispersa nos campi; ii) Interfaces para conferência das informações e confecção e geração de relatórios e indicadores, extração de informações. tanto operacionais quanto gerenciais.

18 Desenvolvimento de novas Acesso controlado via login e senha (assinatura funcionalidades de segurança eletrônica); cadastro de usuários habilitados para operacionalizar o sistema; possibilidade das gravações em vídeo das provas serem armazenadas; rotina de armazenamento dos dados (back-up). 
Tabela 4 (continuação)

\begin{tabular}{|c|c|c|c|}
\hline Etapas (fases) & $\mathbf{N}^{\mathbf{o}}$ & Atividades & Benefícios (ganhos) esperados \\
\hline \multirow[t]{9}{*}{$\begin{array}{l}\text { Implementação/ } \\
\text { Validação }\end{array}$} & 19 & $\begin{array}{l}\text { Criar casos de } \\
\text { testes/protótipos. }\end{array}$ & Vide ação análoga número 7. \\
\hline & 20 & Realizar testes de usabilidade. & Vide ação análoga número 8. \\
\hline & 21 & Realizar testes de sistema. & Vide ação análoga número 9. \\
\hline & 22 & Gerar os relatórios dos testes. & Vide ação análoga número 10. \\
\hline & 23 & $\begin{array}{l}\text { Efetuar ajustes e correções pré- } \\
\text { implementação. }\end{array}$ & Vide ação análoga número 11. \\
\hline & 24 & $\begin{array}{l}\text { Realizar treinamentos com } \\
\text { todos os membros das } \\
\text { Comissões Locais de } \\
\text { Concursos antes de } \\
\text { implementar as alterações. }\end{array}$ & $\begin{array}{l}\text { Familiarizar os usuários com as novas funções e, } \\
\text { consequentemente, com o novo fluxo (com } \\
\text { menor número de ações operacionais) derivado } \\
\text { do conjunto de alterações criado. } \\
\text { Complementarmente, busca padronizar a atuação } \\
\text { das CLC's e reforçar a necessidade de } \\
\text { conferências no decorrer dos certames. }\end{array}$ \\
\hline & 25 & $\begin{array}{l}\text { Implementar as alterações à } \\
\text { produção. }\end{array}$ & $\begin{array}{l}\text { Uma análise pormenorizada deve verificar se } \\
\text { todos os campi possuem as condições } \\
\text { necessárias (ex. sala em que a seleção ocorra } \\
\text { com acesso a rede institucional para a efetiva } \\
\text { comunicação entre sistemas e validações de } \\
\text { segurança; avaliações satisfatórias de seus } \\
\text { membros no treinamento, etc.) para receber as } \\
\text { atualizações ao mesmo tempo, o que pode levar a } \\
\text { cronogramas distintos de implementação por } \\
\text { unidade. }\end{array}$ \\
\hline & 26 & $\begin{array}{l}\text { Avaliar a eficácia e a } \\
\text { efetividade das soluções } \\
\text { aplicadas (entrevistas, } \\
\text { questionários). }\end{array}$ & $\begin{array}{l}\text { Controle das ações e a aferição da satisfação dos } \\
\text { usuários. }\end{array}$ \\
\hline & 27 & $\begin{array}{l}\text { Definir o Suporte, o } \\
\text { Atendimento, os Níveis de } \\
\text { Serviço e de Gestão do } \\
\text { Conteúdo, e fornecer os canais } \\
\text { apropriados para atendimento } \\
\text { das demandas oriundas do uso } \\
\text { do Software. }\end{array}$ & $\begin{array}{l}\text { Prover o suporte técnico necessário aos usuários } \\
\text { para manutenção e evolução do Software. }\end{array}$ \\
\hline
\end{tabular}

Nota. Fonte: Elaborada pelos autores.

As medidas dispostas na proposição demandarão a atuação dos profissionais de TI da Universidade, em conjunto com a área requisitante, medidas essas preferencialmente agregadas na forma de um projeto, em conformidade com os procedimentos institucionais, de modo a permitir o acompanhamento e a integração de todas as ações envolvidas. Com isso, pretende-se valorizar a iniciativa interna, incentivando a Instituição a incorporar esse trabalho para aproveitar as oportunidades que surgiram justamente com a implantação do Software.

Partindo do pressuposto de que as eventuais barreiras às mudanças que podem vir a surgir em mudanças substanciais estão parcialmente superadas, haja vista que o Software objeto da pesquisa encontra-se em uso.

A execução do projeto será compreendida em atividades que ocorrerão distribuídas em etapas, conforme a natureza das intervenções, classificadas em: de planejamento/preparação, de 
desenvolvimento e de implementação/validação. Na etapa de desenvolvimento, dividimos em duas fases: a corretiva e a adaptativo-evolutiva, em que a primeira também conterá fases comuns às etapas de implementação e validação, devido a seu caráter emergencial. Deste modo, teremos a seguinte distribuição numérica das atividades: Etapa de Preparação - da 1 a 5; Etapa de Desenvolvimento - da 6 a 13 (fase corretiva), e da 14 a 18 (fase adaptativo-evolutiva); Etapa de Implementação/Validação - da 19 a 27.

$\mathrm{Na}$ Tabela 4, dispomos as atividades previstas, ordenando-as conforme as etapas e as fases descritas, as quais ainda são passíveis de serem revistas e reordenadas durante o processo de aprovação do escopo do projeto (atividade 5). A duração estimada para introdução da proposição é de 1 ano, em analogia ao prazo concedido para adequação ao SEI (Decreto $\left.{ }^{\circ} 8.539,2015\right)$.

Em relação às atividades de planejamento e preparação (1 a 5), temos como vantagem o conhecimento tácito (prático) dos envolvidos direta e indiretamente no processo, os quais possuem conhecimento acumulado após anos de experiência. Inclusive, o DTIC possui Know-how em levantamentos dessa natureza, haja vista as pesquisas sobre TI que realiza junto a alunos e servidores (UNIPAMPA, 2017b).

O conjunto de ações de validação (de 7 a 11, e de 19 a 23), como fase de testes descrita em Somerville (2011), salienta-se, é o que pretende garantir a compatibilidade entre tecnologia e usuário descrita em Goodhue e Thompson (1995), a importância da utilidade em Tolentino et al. (2007), das alterações perante os usuários (membros das CLC's, da banca examinadora, servidores da Divisão de Concursos, gestores) e, conforme Darwish e Rizk (2015) e Perácio (2017), respectivamente, contribuem positivamente para um desenvolvimento bem-sucedido de Software e sobre a disposição de continuidade de uso do sistema.

É importante ressaltar termos duas entregas principais ao usuário (em 12 e 25), sendo a primeira de menor complexidade, concentrada nas parametrizações, e a seguinte maior, envolvendo as novas funcionalidades e a integração de sistemas, para a qual se fazem necessários treinamentos (atividade 24), em sintonia ao disposto na literatura com destaque para Cresswell et al. (2013).

A criação de relatórios e indicadores estatísticos (atividade 17) pretende qualificar o Software para orientar decisões gerenciais, pois qualquer dado previamente registrado no sistema se tornará uma variável de análise. Por exemplo, seria possível correlacionar o volume de certames ao número de membros das CLC`s, permitindo embasamento técnico para se definir qual o número ideal de membros por campi, com base no volume de certames. O histórico será de grande valia para fornecer informações relevantes para mobilização de recursos a fim de maximizar o desempenho das seleções.

Ao alinhar com as condições já existentes na Universidade, pode-se reconhecer que a UNIPAMPA encontra-se preparada do ponto de vista da capacidade ambidestra, em consonância ao descrito em Napier, Mathiassen, Robey (2011) e Tonelli et al. (2016), ao prover suporte e manutenção aos sistemas e ativos de Software atuais, ao mesmo tempo em que consegue dirigir esforços no desenvolvimento de sistemas novos, possuindo, em seus procedimentos, fluxogramas de processos, tanto para "Novo requisito programado" (Construção de uma nova aplicação) quanto de "Requisito não previsto ou falhas/defeitos" (Solução de problemas em sistema em execução) (UNIPAMPA, 2017c).

\section{Conclusões e Contribuição Tecnológica/Social}

Esta pesquisa buscou atender ao objetivo de propor melhorias no Software utilizado nas provas de Concursos Públicos e Processos Seletivos Simplificados na Universidade Federal do Pampa. A aplicação do Diagnóstico, em conjunto com os achados teóricos e a observação dos processos, todavia, permitiu verificar oportunidades para além da solução estanque dos equívocos pontuais nos registros, de modo a alçar o Software corrente para outro patamar, isto é, com vistas a torná-lo um Software efetivamente gestor. 
Considerando que o objetivo inicialmente posto foi alcançado, as proposições posicionam o sistema em situação que lhe proporcione um ciclo de vida sustentável, qual seja, pela integração ao portfólio institucional, para que receba tratamento profissional e permanente, a fim de se adaptar às evoluções tecnológicas do campo de sistemas de informação e ao desempenho de seus usuários.

A contribuição aplicada do Software aperfeiçoado para a gestão do ingresso de docentes na Universidade tem potencial de produzir efeitos subsequentes sobre as pessoas, fluxos de trabalho, processos, tecnologia e estrutura organizacional, acompanhando, assim, a evolução do Software para melhorar objetivamente o padrão de qualidade do serviço público em questão. Acerca dos benefícios, trata-se de qualificar o papel desempenhado pelos membros das comissões e das bancas examinadoras atuantes nos processos, valorizando as suas competências precípuas, e de fortalecer os canais de comunicação e a importância da informação armazenada, tratada e compartilhada, a ponto de amenizar as problemáticas multicampi e subsidiar ações de gestão tempestivas em respostas às adversidades, aprimorando o grau de envolvimento da unidade matriz junto às locais. Além do mais, a pressão cada vez maior da sociedade na direção do Estado impõem que os servidores públicos sejam dotados do suporte técnico adequado, a altura dos desafios contemporâneos, sendo as ferramentas baseadas no uso de tecnologia da informação, como essa, um caminho nesse sentido.

Ao mesmo tempo, há o reconhecimento de que se trata de um primeiro passo, devido não somente à complexidade dos esforços subsequentes, mas, sobretudo, aos diversos atores que devem estar envolvidos de modo a contribuir para o desenvolvimento pleno das sugestões iniciais aqui descritas.

Em termos de sua relevância social, o estudo pode extrapolar as fronteiras institucionais, servindo de referência para outras organizações, principalmente às regradas pelas mesmas leis ou com ritos semelhantes para recrutamento e seleção de pessoal docente, ao que pese a similaridade perceptível nos editais de concursos para os cargos do magistério superior, em particular no âmbito das IFES, revelando o potencial de compartilhamentos e personalização do Software, podendo se inspirar nos moldes do projeto PEN-SEI (Ministério do Planejamento, Orçamento e Gestão, n.d.).

À luz dos princípios da Administração Pública expressos na Carta Magna, as melhorias propostas têm condições de aproximar o discurso da prática. Ao imprimir maior impessoalidade, promove a imagem de lisura dos trabalhos, reforçando o aspecto legal e elevando a moralidade da esfera pública. Além disso, a eficiência se apresenta ao tornar o ambiente mais controlado e ágil, inclusive na maior celeridade esperada na publicidade dos atos durante e pós provas. No limite, a conjuração dos princípios tende à excelência.

O estudo detalhado neste relato contribui, ainda, demonstrando a importância de se adotar uma visão multidisciplinar e, portanto, aberta à contribuição de outras ciências e paradigmas afins, com a devida contextualização necessária, para se construir soluções as mais adequadas possíveis, e não tão somente aplicar soluções prontas, muitas vezes aquém dos problemas encontrados.

Por fim, como indicativos de estudos futuros, aponta-se a proeminente discussão sobre Gestão de Riscos na Administração Pública, fomentada principalmente pelos órgãos de auditoria e controle, como uma ótica promissora para se analisar um processo de concursos públicos, sobretudo na etapa das provas. Logo, advoga-se para que outros componentes do processo de Recrutamento e Seleção na Administração Pública Federal sejam estudados, ou, ainda, do macroprocesso de admissão de pessoal, pelo incipiente número de publicações contemplando essas temáticas.

\section{Referências}

Bergue, S. T. (2010). Gestão de pessoas em organizações públicas (3a ed.). Caxias do Sul: Educs.

Bernus, P., Mertins, K., \& Schmidt, G. J. (2006). Handbook on architectures of information systems. 
Handbook on architectures of information systems (2nd ed). Berlin: Springer. https://doi.org/10.1007/b137905

Cepik, M., Possamai, A. J., Canabarro, D. R., Freitas, I., Oliveira, A., \& Samrsla, E. (2009). Avaliando o desempenho do governo eletrônico no Brasil: $O$ índice de qualidade de e-serviços governamentais. Anais da Conferência Web W3C. São Paulo, 1. Recuperado de https://www.ufrgs.br/cegov/files/documento_236.pdf

Clarke, P., O'Connor, R. V., \& Leavy, B. (2016). A complexity theory viewpoint on the software development process and situational context. Proceedings of the 2016 International Conference on Software and System Process (ICSSP 2016), San Francisco, CA.

Cooper, D. R., \& Schindler, P. S. (2016). Métodos de pesquisa em administração (12a ed.). São Paulo: McGraw Hill Brasil.

Cresswell, K. M., Bates, D. W., \& Sheikh, A. (2013). Ten key considerations for the successful implementation and adoption of large-scale health information technology. Journal of the American Medical Informatics Association, 20(e1), e9-e13. http://dx.doi.org/10.1136/amiajnl2013-001684

Darwish, N. R., \& Rizk, N. M. (2015). Multi-dimensional success factors of agile software development projects. International Journal of Computer Applications, 118(15), 23-30. http://dx.doi.org/10.5120/20823-3453

Davenport, T. H. (2013). Process innovation: Reengineering work through information technology. Boston, MA: Harvard Business School Press.

Decreto $n^{\circ} 8.539$, de 8 de outubro de 2015. (2015). Dispõe sobre o uso do meio eletrônico para a realização do processo administrativo no âmbito dos órgãos e das entidades da administração pública federal direta, autárquica e fundacional. Recuperado de http://www.planalto.gov.br/ccivil_03/_Ato2015-2018/2015/Decreto/D8539.htm

De Muylder, C. F., Nicholls, J. La Falce, J. L., Martins, H. C., \& Dias, A. T. (2013). Sistema de informação e inovação em órgão público de Minas Gerais: Sistema de autorização de impressão de documentos fiscais. TPA-Teoria e Prática em Administração, 3(2), 175-199.

Evangelista, W. G., \&, Souza, J., Neto (2016). Modelo de avaliação da capacidade das organizações da administração pública federal para a adoção de software as a service (SaaS) público. Revista do Serviço Público, 67(2), 173-202. http://dx.doi.org/10.21874/rsp.v67i2.1477

Fleischmann, M., Amirpur, M., Grupp, T., Benlian, A., \& Hess, T. (2016). The role of software updates in information systems continuance - An experimental study from a user perspective. Decision Support Systems, 83, 83-96. http://dx.doi.org/10.1016/j.dss.2015.12.010

Governo Eletrônico. Ministério do Planejamento, Orçamento e Gestão. (2016, julho 25). Implementação de software livre. Recuperado 4 fevereiro, 2017, de https://www.governodigital.gov.br/sobre-oprograma/estrutura-governo-eletronico/comites-tecnicos/implementacao-de-software-livre

Furneaux, G. B. (2012). Task-technology fit theory: A survey and synopsis of the literature. In Y. K. Dwivedi \& M. R. Wade (Eds.), Information systems theory: Explaining and predicting our digital society (Vol. 1, pp. 87-102). New York, NY: Springer. http://dx.doi.org/10.1007/978-1-44196108-2_5

Ivan, C., Leal, S., Quintella, S. F., Oswaldo, F., Dornelles, N., Simonsen, R., ... Lundgren, M. (2015). Cadernos FGV Projetos nº25 - Concursos públicos, avaliações e certificações. FGV Projetos. Recuperado de http://fgvprojetos.fgv.br/publicacao/cadernos-fgv-projetos-no25-concursospublicos-avaliacoes-e-certificacoes 
Kanaane, R., Fiel, A., Filho, \& Ferreira, M. das G. (2010). Gestão pública: Planejamento, processos, sistemas de informação e pessoas. São Paulo: Atlas.

Laudon, K. C., \& Laudon, J. P. (2010). Sistemas de informação gerenciais (9a ed). São Paulo: Pearson Prentice Hall.

Marchioro, D. F. Z., Nedel, D. L., Voss, D. M. da S., Kakuno, E. M., Fonseca, G. D. da, Negrão, M. M. R., Irala, V. B., \& Ferreira, V. L. D. (2007). A UNIPAMPA no contexto atual da educação superior. Avaliação: Revista da Avaliação da Educação Superior, 12(4), 703-717. http://dx.doi.org/10.1590/S1414-40772007000400008

Mell, P., \& Grance, T. (2011). The NIST definition of cloud computing. Retrieved from https://nvlpubs.nist.gov/nistpubs/Legacy/SP/nistspecialpublication800-145.pdf. http://dx.doi.org/10.6028/NIST.SP.800-145

Ministério do Planejamento, Orçamento e Gestão. (n.d.). PEN-SEI - Processo Eletrônico Nacional (PEN). Recuperado 25 outubro, 2017, de http://www.planejamento.gov.br/pensei/processoeletronico-nacional-pen

Ministério do Planejamento, Orçamento e Gestão. (2016). EGD - Estratégia de governança digital da administração pública federal 2016-19. Brasília: MP. Recuperado de https://www.governoeletronico.gov.br/documentos-e-arquivos/egd-estrategia-de-governancadigital-da-administracao-federal-2016-2019.pdf/at_download/file

Ministério do Planejamento, Orçamento e Gestão. Secretaria de Logística e Tecnologia da Informação. (2012). Processo de Software para o SISP: Versão 1.0. Brasília: MP. Recuperado de http://www.sisp.gov.br/pswsisp/wiki/download/file/guiaPsw

Ministério do Planejamento, Orçamento e Gestão. Secretaria de Tecnologia da Informação. Departamento do Governo Digital. gov.br ePING Padrões de Interoperabilidade de Governo Eletrônico: documento de Referência. (2017). Recuperado de https://www.governoeletronico.gov.br/documentos-e-arquivos/e-PING_v2017_20161221.pdf

Napier, N. P., Mathiassen, L., \& Robey, D. (2011). Building contextual ambidexterity in a software company to improve firm-level coordination. European Journal of Information Systems, 20(6), 674-690. http://dx.doi.org/10.1057/ejis.2011.32

Neiva, S. A. P. (2015). Dimensões organizacionais da Universidade Federal do Pampa: Uma análise qualitativa da estrutura multicampi (Dissertação de mestrado). Universidade Federal de Goiás, Catalão, GO, Brasil.

Nez, E. (2016). Os dilemas da gestão de universidades multicampi no Brasil. Revista Gestão Universitária na América Latina, 9(2), 131-153. http://dx.doi.org/10.5007/19834535.2016v9n2p131

Perácio, L. B. (2017). Inovação na administração pública: Aplicação do modelo TAM/TTF para avaliação do sistema de controle de afastamento na UFMG (Tese de mestrado). Universidade FUMEC, Belo Horizonte, MG, Brasil.

Pires, M. C. F. S., Prado, L. S., Ferreira, D. A., \& Rita, L. P. S. (2016). Inovação na gestão pública no Brasil: Análise dos limites e possibilidades. Anais do Congresso Nacional de Mestrados Profissionais em Administração Pública. Curitiba, PR, Brasil. Recuperado de http://www.profiap.org.br/profiap/eventos/2016/i-congresso-nacional-de-mestradosprofissionais-em-administracao-publica/anais-do-congresso/40610.pdf

Pressman, R. S. (2010). Software engineering: A practitioner's approach (7th ed.). New York: McGraw-Hill (Higher Education). 
Roses, L. K., Windmöller, A., \& Carmo, E. A. do (2016). Favorability conditions in the adoption of agile method practices for Software development in a public banking. Journal of Information Systems and Technology Management, 13(3), 439-458. http://dx.doi.org/10.4301/S180717752016000300005

SciELO. (2017). Guia para o registro e publicação de Errata. Recuperado em http://www.scielo.org/local/File/Guia_para_o_registro_e_publicacao_de_Errata.pdf

Silva, N. Jacobsen, A. L., Almeida, M. S., \& Olivo, L. C. C. (2013). O sistema "UFSC sem papel” sob a perspectiva da inovação. Revista de Ciências da Administração, 15(35), 11-22. http://dx.doi.org/10.5007/2175-8077.2013v15n35p11

Silva, J. H. C. (2011). O papel do Tribunal de Contas no controle da legalidade sobre os concursos públicos. Interface - Revista do Centro de Ciências Sociais Aplicadas, 8(2), 8-23.

Software Público Brasileiro. Ministério do Planejamento, Orçamento e Gestão. (2014, dezembro 4). $O$ que é o software público. Recuperado 3 abril, 2017, de https://softwarepublico.gov.br/social/spb/o-que-e-o-software-publico

Sommerville, I. (2011). Software engineering (9th ed.). Boston: Addison-Wesley.

Tolentino, R. S., Tolentino, R. J. V., Gonçalves, C., Filho, \& Souki, G. Q. (2007). Análise do desempenho individual de usuários de sistemas de informação: Um estudo integrativo dos modelos TAM e TTF. Revista Faces FUMEC, 6(2), 91-103.

Tonelli, A. O., Zambalde, A. L., Brito, M. J., \& Bermejo, P. H. S. (2016). The theory and practice and the development of ambidextery in software innovation process. Brazilian Business Review, 13(3), 26-49. http://dx.doi.org/10.15728/bbr.2016.13.3.2

Universidade Federal do Pampa. (2013). GCP 3.6 - Gerenciador de Concursos Públicos - Manual de Utilização Rápida. Recuperado de http://cc.alegrete.UNIPAMPA.edu.br/gcp/versions/3.7/Manual_GCP_3.6.pdf

Universidade Federal do Pampa. (2014). Resolução n ${ }^{\circ}$ 82, de 30 de outubro de 2014. Recuperado 27 março, 2017, de http://www.UNIPAMPA.edu.br/portal/documentos/doc_download/3027-

Universidade Federal do Pampa. (2015). Resolução n ${ }^{0}$ 117, de 22 de outubro de 2015. Recuperado de http://www.UNIPAMPA.edu.br/portal/documentos/doc_details/3410-

Universidade Federal do Pampa. (2017c). Desenvolvimento de Sistemas. Recuperado 22 fevereiro, 2017, de http://ntic.UNIPAMPA.edu.br/processos/desenvolvimento-de-sistemas/

Universidade Federal do Pampa. (2017b). PDTIC. Recuperado 3 abril, 2017, de http://ntic.UNIPAMPA.edu.br/pdtic/

Universidade Federal do Pampa. (2017a). Universidade. Recuperado 20 fevereiro, 2017, de http://novoportal.UNIPAMPA.edu.br/novoportal/universidade

Vasconcelos, J. B., Kimble, C., Carreteiro, P., \& Rocha, Á. (2017). The application of knowledge management to Software evolution. International Journal of Information Management, 37(1), 1499-1506. http://dx.doi.org/10.1016/j.ijinfomgt.2016.05.005

Yusof, M. M., Papazafeiropoulou, A., Paul, R. J., \& Stergioulas, L. K. (2008). Investigating evaluation frameworks for health information systems. International Journal of Medical Informatics, 77(6), 377-385. http://dx.doi.org/10.1016/j.ijmedinf.2007.08.004

Zigurs, I., \& Buckland, B. K. (1998). A theory of task/technology fit and group support systems effectiveness. MIS Quarterly, 22(3), 313-334. http://dx.doi.org/ 10.2307/249668 


\section{Dados dos Autores}

Matheus Boni Barbosa

Rua Gomes Carneiro, 01, 96010-610, Pelotas, RS, Brasil. E-mail: bonibarbosa@ gmail.com. https://orcid.org/0000-0002-20837225

Elvis Silveira-Martins

Rua Gomes Carneiro, 01, 96010-610, Pelotas, RS, Brasil. E-mail: elvis.professor@gmail.com. https://orcid.org/0000-00023189-3767 